\title{
Insulin sensitisation affects lipoprotein lipase transport in type 2 diabetes: role of adipose tissue and skeletal muscle in response to rosiglitazone
}

\author{
G. D. Tan • G. Olivecrona • H. Vidal • K. N. Frayn • \\ F. Karpe
}

Received: 24 April 2006 / Accepted: 30 May 2006 / Published online: 1 August 2006

(C) Springer-Verlag 2006

\begin{abstract}
Aims/hypothesis Lipoprotein lipase (LPL) is produced by adipose tissue and skeletal muscle, but acts on plasma lipoproteins after being transported to endothelial binding sites. Insulin resistance is associated with decreased plasma LPL mass. We investigated the effects of insulin sensitisation on tissue-specific LPL expression and transport in patients with type 2 diabetes.

Materials and methods Arterio-venous gradients of plasma LPL activity and mass across adipose tissue and skeletal muscle were measured in 16 type 2 diabetic patients in a double-blind, placebo-controlled, cross-over randomised trial of rosiglitazone. In vivo LPL rate of action was assessed by tissue-specific arterio-venous triglyceride concentration gradients. $L P L \mathrm{mRNA}$ was quantified in adipose tissue and skeletal muscle biopsies.

Results Adipose tissue released large quantities of inactive LPL $(p<0.001)$; skeletal muscle released small amounts of
\end{abstract}

G. D. Tan $\cdot$ K. N. Frayn

OCDEM, Nuffield Department of Clinical Medicine,

University of Oxford,

Oxford, UK

G. Olivecrona

Department of Medical Biosciences, Physiological Chemistry,

Umeå University,

Umeå, Sweden

H. Vidal

INSERM U.449/INRA U.1235, Laennec Faculty of Medicine, Claude Bernard University of Lyon,

Lyon, France

F. Karpe $(\square)$

OCDEM, Churchill Hospital,

Oxford OX3 7LJ, UK

e-mail: fredrik.karpe@ocdem.ox.ac.uk active LPL $(p<0.01)$. Rosiglitazone increased adipose tissue release of LPL mass $(+35 \%, p=0.04)$ and decreased the release of active LPL from skeletal muscle $(-57 \%, p=0.03)$. Rosiglitazone increased adipose tissue and skeletal muscle LPL mRNA, but did not affect adipose tissue LPL rate of action or activity. Adipose tissue release of LPL mass correlated with systemic LPL mass concentrations $(r=0.47$, $p=0.007$ ), suggesting that the rate of adipose tissue release of LPL mass is a major determinant of systemic LPL mass concentrations.

Conclusions/interpretation LPL transport from adipose tissue and skeletal muscle are regulated differently. In adipose tissue, rosiglitazone increases $L P L$ mRNA abundance and LPL transport rate and possibly increases endothelial binding sites for LPL, but affects neither tissue LPL activity nor LPL rate of action.

Keywords Lipases · Thiazolidinedione .

Very-low-density lipoprotein

\section{Abbreviation \\ LPL lipoprotein lipase}

\section{Introduction}

Lipoprotein lipase (LPL) is the key enzyme in the removal of triglycerides from plasma. Indeed, states in which LPL activity is decreased, such as insulin resistance and type 2 diabetes, are associated with elevated plasma triglyceride concentrations. The mechanism by which this occurs is unclear. Part of the explanation may lie in the decreased abundance of active LPL on endothelial surfaces, a finding demonstrated by injecting heparin i.v. into subjects with 
type 2 diabetes to release LPL from the endothelium into the plasma and then quantifying plasma LPL activity [1-4]. Furthermore, type 2 diabetes and insulin resistance have also been linked to low circulating LPL concentrations of LPL protein mass $[5,6]$. Neither of the two forms of LPL present in the circulation, a very small amount of active LPL and a larger amount of inactive LPL, is related to the abundance of active LPL on endothelial surfaces, as measured in post-heparin plasma [7]. It is, however, possible that the inactive LPL in the circulation reflects the overall generation of LPL in peripheral tissue, but this hypothesis has never been formally tested. Indeed, it has been suggested that the concentration of circulating LPL is a global marker for insulin resistance [8] and also related to cardiovascular disease [9]. However, the measurement of circulating LPL protein mass, with or without i.v. heparin, has not previously been associated with tissue-specific regulation of LPL. As adipose tissue LPL mRNA abundance is regulated by insulin, TNF- $\alpha$, catecholamines and a number of other factors $[10,11]$, these tissue-specific changes are likely to be of importance in type 2 diabetes and insulin resistance.

Adipose tissue $L P L$ mRNA abundance is upregulated postprandially by insulin, although a large proportion of the rapid fasted-to-fed increase in active enzyme at endothelial binding sites has been ascribed to post-transcriptional changes with little or no changes in LPL mRNA. Studies of rat adipose tissue suggest that the cellular secretion of LPL protein is continuous. In the presence of insulin, LPL remains mostly active $[12,13]$. Conversely, in the fasted state the inactive form of LPL predominates. The transition to the inactive form requires transcription of an as yet unknown gene [14], the product of which presumably acts on the active form of LPL.

Little is known about the transport of LPL from the adipocyte to the endothelium, but LPL can undergo extracellular degradation by matrix metalloproteinases [15]. The regulation of the density, distribution and relative affinity of endothelial binding sites for LPL between tissues is largely unknown and its regulation by nutritional status has only been studied in the rat heart [16]. Increased replenishment of active LPL on endothelial binding sites in adipose tissue is therefore an important aspect of the rapid upregulation of LPL seen in the postprandial state.

The production and transport processes of LPL in vivo can be examined by using arterio-venous techniques to measure release of active and inactive LPL by specific tissues. We have previously reported that LPL transport differs between adipose tissue and skeletal muscle of healthy humans [17]. Adipose tissue secretes substantial quantities of inactive LPL, whilst at the same time extracting part of the small amount of active LPL presented to it by the arterial circulation. In contrast, skeletal muscle releases less LPL overall, although a larger fraction of this is active than that released by adipose tissue.

In light of the key role played by insulin in LPL activity in adipose tissue, and the abnormalities of LPL metabolism in type 2 diabetes, we applied the same arterio-venous technology to study LPL transport in insulin-resistant type 2 diabetic patients undergoing insulin sensitisation by rosiglitazone.

\section{Subjects, materials and methods}

\section{Subjects and protocol}

The results on metabolic and physiological responses to rosiglitazone in 24 patients with type 2 diabetes have recently been reported [18]. Sixteen of these subjects had full sets of plasma samples suitable for LPL measurements and were used for this analysis. The mean baseline characteristics and the responses to rosiglitazone of the 16 subjects presented here were similar to those of the 24 subjects included in the original study [18] (Table 1).

This was a double-blind, placebo-controlled, cross-over study. Subjects were randomised into one of two groups: rosiglitazone $4 \mathrm{mg}$ twice daily for 12 weeks followed by placebo for 12 weeks, or vice versa. At the end of each 12week treatment period, patients attended the clinical research unit after a 10-h overnight fast for metabolic investigation. Vigorous exercise and alcohol were avoided for $24 \mathrm{~h}$ before each study.

To assess tissue-specific in vivo metabolism and LPL function in humans, we measured arterio-venous differences of triglycerides [18], glycerol [18], LPL activity and LPL mass across adipose tissue and skeletal muscle, and also took tissue biopsies for measurement of $L P L$ mRNA expression and LPL tissue activity.

Arterialised blood was obtained from a vein draining a heated hand. Venous blood from the forearm, reflecting the venous drainage of skeletal muscle, was taken retrogradely

Table 1 Clinical characteristics of the patients

\begin{tabular}{lllll}
\hline & $\begin{array}{l}\text { Placebo } \\
(n=16)\end{array}$ & $\begin{array}{l}\text { Rosiglitazone } \\
(n=16)\end{array}$ & $\begin{array}{l}\text { Change } \\
(\%)\end{array}$ & $p$ \\
\hline Age (years) & $51 \pm 3$ & - & - & - \\
Sex (M/F) & $11 / 5$ & - & - & - \\
$\mathrm{HbA}_{1 \mathrm{c}}(\%)$ & $7.2 \pm 0.2$ & $6.9 \pm 0.2$ & $-4 \%$ & 0.014 \\
$\mathrm{BMI}\left(\mathrm{kg} / \mathrm{m}^{2}\right)$ & $34.1 \pm 1.2$ & $34.6 \pm 1.3$ & $+1.5 \%$ & 0.049 \\
\hline
\end{tabular}

Values are means $\pm \mathrm{SE}$

Statistical significance for effect of treatment was calculated by a Student's paired $t$-test 
from a deep antecubital vein [19]. Venous blood from adipose tissue was obtained from the superficial epigastric vein, as described previously [19]. Heparinised blood samples were taken simultaneously from all three sites in the fasting state and immediately put on ice for separation of plasma at $+4^{\circ} \mathrm{C}$; plasma was frozen at $-80^{\circ} \mathrm{C}$ within $1 \mathrm{~h}$. To prevent contamination of the blood from the forearm vein with blood from the hand, a wrist cuff was inflated to above the systolic blood pressure (either to $30 \mathrm{mmHg}$ above the systolic blood pressure or to $200 \mathrm{mmHg}$, whichever value was higher) for $3 \mathrm{~min}$ before samples were taken. Subcutaneous abdominal adipose tissue blood flow was measured by ${ }^{133} \mathrm{Xe}$ washout. Forearm muscle blood flow was assessed by strain-gauge plethysmography. Skeletal muscle and adipose tissue biopsies were taken under local anaesthesia (1\% lignocaine) $5 \mathrm{~h}$ after a standardised meal containing $40 \mathrm{~g}$ fat and $40 \mathrm{~g}$ carbohydrate.

Biopsies of s.c. abdominal adipose tissue were taken with a 12-gauge needle, and muscle biopsies were taken from the vastus lateralis muscle using a percutaneous needle technique $5 \mathrm{~h}$ after ingestion of a standardised meal, as described previously [18]. Tissue samples were immediately frozen in liquid nitrogen and stored at $-70^{\circ} \mathrm{C}$ for later mRNA quantification and LPL activity in adipose tissue.

The study was approved by the Oxfordshire Clinical Research Ethics Committee, and all subjects gave their written informed consent.

\section{LPL measurements}

The snap-frozen piece of adipose tissue was weighed, thawed and immediately homogenised using a homogeniser (Polytron PT-MR 3000; Kinematica, Littau, Switzerland) in nine volumes of ice-cold buffer with detergents and proteinase inhibitors $\left(0.025 \mathrm{~mol} / 1 \mathrm{NH}_{3}, 5 \mathrm{mmol} / 1 \mathrm{Na}_{2}\right.$ EDTA, and per $\mathrm{ml}$ : $1 \mathrm{mg}$ BSA [Fraction V; Sigma-Aldrich Sweden, Stockholm, Sweden], $10 \mathrm{mg}$ Triton X-100, $1 \mathrm{mg}$ SDS and 5 IU heparin). One tablet of proteinase inhibitors (Complete Mini; Roche Diagnostics, Rotkreuz, Switzerland) was added to $50 \mathrm{ml}$ of this buffer and the $\mathrm{pH}$ was adjusted to 8.2 [20]. The tissue homogenates were centrifuged for $15 \mathrm{~min}$ at $2,500 \mathrm{~g}$, after which the intermediate phase (between the floating fat droplets and the pellet) was used for assay of LPL activity.

For the assay of plasma LPL activity, a lipid emulsion with the same composition as Intralipid $10 \%$ was used (soy bean triglycerides emulsified with egg yolk phosphatidylcholine) [20], although the emulsion also contained a trace amount of $\left[{ }^{3} \mathrm{H}\right]$ oleic acid-labelled triolein (kindly prepared by Fresenius Kabi, Stockholm, Sweden). The incubations were carried out for $120 \mathrm{~min}$ at $25^{\circ} \mathrm{C}$ in a total volume of $200 \mu \mathrm{l}$ containing $0.1 \mathrm{~mol} / 1 \mathrm{Tris}-\mathrm{HCl}, \mathrm{pH} 8.5,0.1 \mathrm{~mol} / 1 \mathrm{NaCl}$ and
$2 \mathrm{mg} / \mathrm{ml}$ triglycerides from the emulsion, $60 \mathrm{mg}$ BSA, $0.1 \mathrm{mg}$ heparin and $50 \mu \mathrm{l}$ fasted rat serum as a source of the activator apolipoprotein CII. Each sample was analysed in triplicate. The fatty acids were extracted according to Dole's method as previously described [7], and the lipase activity is expressed in milliunits per milliliter of plasma or milliunits per gram of adipose tissue, where $1 \mathrm{mU}$ corresponds to release of $1 \mathrm{nmol}$ fatty acid/min. The sample volumes were 3 and $20 \mu \mathrm{l}$ from adipose tissue homogenates and plasma, respectively. All samples were assayed in triplicate, from which mean values were calculated. For selective measurement of plasma LPL activity, plasma samples were preincubated for $2 \mathrm{~h}$ on ice with one-half volume of goat $\operatorname{IgG}$ raised against human hepatic lipase to inhibit all hepatic lipase activity $[7,21]$.

LPL protein mass was determined by ELISA as previously described [20], using immunoaffinity-purified chicken antibodies raised against bovine LPL for capture, and the monoclonal antibody 5D2, also raised against bovine LPL, for detection (a kind gift from J. Brunzell, Dept of Medicine, University of Washington, Seattle, WA, USA). For most samples, mean values were calculated from measurements of three different dilutions $(1 / 5,1 / 10$ and $1 / 20$ for adipose tissue and $1 / 10,1 / 20$ and $1 / 40$ for plasma). LPL purified from bovine milk was used as standard for the assay. The absolute concentrations of LPL mass appear to be considerably lower than previously reported [17]. The most likely explanation for this discrepancy is that the concentration of the human LPL standard previously used had been underestimated, since it was based on measurement of LPL activity. The standard preparation may have contained some inactive LPL protein.

\section{Calculations}

The tissue-specific LPL rate of action was calculated by multiplying the arterio-venous difference of plasma triglyceride concentrations, corrected for free glycerol, across either adipose tissue or skeletal muscle, with the tissue blood flow, accounting for the haematocrit. The transport rates of LPL mass and activity were calculated by multiplying the arterio-venous differences for plasma LPL mass concentration or activity with blood flow and accounting for the haematocrit. When whole-body adipose tissue LPL transport rate was calculated, the per unit transport rates were multiplied by the estimated fat mass based on age, sex and BMI.

\section{Statistics}

Within-group and treatment results are expressed as means with 95\% CIs. Treatment differences were calculated with either Student's paired $t$-test or Wilcoxon's signed rank test 
when appropriate due to skewness. Pearson correlation coefficients were calculated after checking for normal distribution and Spearman rank correlations were used for skewed data.

\section{Results}

Plasma LPL activity and mass in response to rosiglitazone

LPL activity in systemic (arterialised venous) plasma was low: $0.35 \mathrm{mU} / 1$ with a $95 \% \mathrm{CI}$ of $0.28-0.42$ within the 16 diabetic subjects. There was no change in LPL activity in response to rosiglitazone $(-3 \%, \mathrm{NS})$ (Table 2). In contrast, there was a clear increase in the systemic concentration LPL mass in response to rosiglitazone $(+22 \%, p=0.01)$.

Tissue-specific handling of LPL

\section{Forearm}

LPL activity was consistently higher $(+45 \pm 11 \%, p<0.001)$ in forearm venous blood than in arterialised, showing that the forearm released active LPL (Table 3). Active LPL was still released from the forearm after rosiglitazone treatment $(+26 \pm 9 \%$ compared with arterialised concentration, $p<0.001$ ), and the transport rate of LPL activity, in which the forearm blood flow was factored in, was reduced by $57 \pm$ $28 \%$ ( $p=0.03$ ) (Table 3). The release of LPL mass from the forearm showed a different pattern. During placebo treatment the arterio-venous difference in LPL mass as well as the calculated transport rate of LPL from the forearm was so small that it could not be distinguished from zero (Table 3). However, after rosiglitazone the arterio-venous difference for LPL mass appeared to increase slightly and the transport was now quantifiable $\left(2.8 \mathrm{ng} \mathrm{min}^{-1} 100 \mathrm{~g}^{-1}\right.$ tissue, 95\% CI 1.1-4.6). As previously shown [18], the forearm LPL rate of action was unchanged by rosiglitazone, whereas the $L P L$ mRNA content in skeletal muscle was significantly increased $(+73 \pm 30 \%, p=0.04)$ (Table 3$)$. The transport rate of LPL activity and mass was used to estimate the change in specific activity of the released enzyme in response to rosiglitazone. The ratio between LPL activity and mass transport rates was $0.16 \mathrm{mU} / \mathrm{ng}$ during placebo treatment. This was reduced by $81 \%$ in response to rosiglitazone to $0.03 \mathrm{~m} / \mathrm{ng}(p<0.001)$.

\section{Adipose tissue}

Adipose tissue showed a very different pattern compared with the forearm. There was no significant arterio-venous difference of LPL activity across adipose tissue on placebo, whereas a tendency for lower LPL activities in the adipose tissue venous samples compared with arterialised samples was observed after rosiglitazone treatment $(p=0.07)$ (Table 3). The adipose tissue transport rate of LPL activity was also indistinguishable from zero on placebo treatment but significantly negative $(p=0.04)$ after rosiglitazone, indicating uptake of active LPL from the systemic circulation by adipose tissue (Table 3 ). In contrast to the very low transport rates of active LPL from adipose tissue, the arterio-venous difference of LPL mass was high in adipose tissue. On average, adipose tissue venous plasma had approximately $50 \%$ higher LPL mass concentrations compared with the systemic circulation, which contrasted with the forearm where the arterio-venous LPL mass differences were close to zero. Also in contrast to the forearm, the transport rate of LPL mass from adipose tissue was distinct from zero $(p<0.001)$ and increased by $35 \%$ after rosiglitazone treatment $(p=0.04)$ (Table 3$)$. The specific activity of the released enzyme could not be calculated as it would involve negative numbers (for comparison see forearm). Adipose tissue LPL rate of action measured in vivo by the triglyceride extraction across the tissue, and LPL tissue activity (measured in adipose tissue biopsy material) were unchanged by rosiglitazone (Table 3 ). Adipose tissue $L P L$ mRNA expression was increased by $28 \pm 10 \%$ in response to rosiglitazone treatment $(p=0.04)$.

Table 2 Plasma LPL activities and LPL mass concentrations in arterialised venous, forearm venous and adipose tissue venous blood after placebo and rosiglitazone treatment

\begin{tabular}{|c|c|c|c|c|}
\hline Plasma concentrations & Placebo $(n=16)$ & Rosiglitazone $(n=16)$ & Change $(\%)$ & $p$ \\
\hline \multicolumn{5}{|l|}{ LPL activity (mU/ml) } \\
\hline Arterialised & $0.35(0.28-0.42)$ & $0.34(0.29-0.39)$ & -3 & 0.91 \\
\hline Forearm venous & $0.53(0.44-0.61)$ & $0.44(0.36-0.53)$ & -17 & 0.09 \\
\hline Adipose tissue venous & $0.33(0.25-0.41)$ & $0.29(0.23-0.35)$ & -12 & 0.44 \\
\hline \multicolumn{5}{|l|}{ LPL mass $(\mu \mathrm{g} / 1)$} \\
\hline Arterialised & $14.3(11.1-17.5)$ & $17.4(14.3-20.5)$ & +22 & 0.01 \\
\hline Forearm venous & $15.8(12.9-18.6)$ & $20.1(17.0-23.2)$ & +27 & 0.001 \\
\hline Adipose tissue venous & $21.7(17.9-25.5)$ & $25.3(21.3-29.4)$ & +16 & 0.03 \\
\hline
\end{tabular}

Values are means $(95 \% \mathrm{CI})$

Statistical significances between treatments were calculated by a Student's paired $t$-test 
Table 3 LPL activity and mass transport rates across s.c. adipose tissue and forearm, LPL rate of action in adipose tissue and forearm, $L P L$ mRNA expression in adipose tissue and skeletal muscle, and LPL activity in isolated s.c. adipose tissue

\begin{tabular}{|c|c|c|c|c|}
\hline & Placebo $(n=16)$ & Rosiglitazone $(n=16)$ & Change (\%) & $p$ \\
\hline \multicolumn{5}{|l|}{ Forearm/skeletal muscle } \\
\hline LPL activity transport rate $\left(\mathrm{mU} \min ^{-1} 100 \mathrm{~g}^{-1}\right.$ tissue $)$ & $0.21(0.09$ to 0.34$)$ & $0.09(0.04$ to 0.15$)$ & -57 & 0.03 \\
\hline LPL mass transport rate (ng $\min ^{-1} 100 \mathrm{~g}^{-1}$ tissue) & $1.3(-0.7$ to 3.2$)$ & $2.8(1.1$ to 4.6$)$ & +115 & 0.15 \\
\hline$L P L$ mRNA (arbitrary units) & $22(13$ to 32$)$ & $38(19$ to 57$)$ & +73 & 0.04 \\
\hline LPL rate of action ( $\mathrm{nmol} \mathrm{min} \mathrm{m}^{-1} 100 \mathrm{~g}^{-1}$ tissue) & $51(22$ to 79$)$ & $32(10$ to 54$)$ & -37 & 0.21 \\
\hline \multicolumn{5}{|l|}{ Adipose tissue } \\
\hline LPL activity transport rate ( $\mathrm{mU} \min ^{-1} 100 \mathrm{~g}^{-1}$ tissue $)$ & $-0.12(-0.36$ to 0.10$)$ & $-0.12(-0.23$ to -0.01$)$ & +0 & 0.96 \\
\hline LPL mass transport rate (ng $\min ^{-1} 100 \mathrm{~g}^{-1}$ tissue) & $7.1(3.5$ to 10.6$)$ & $9.6(6.8$ to 12.5$)$ & +35 & 0.04 \\
\hline$L P L$ mRNA (arbitrary units) & $170(129$ to 211$)$ & $217(173$ to 261$)$ & +28 & 0.01 \\
\hline LPL activity in tissue $\left(\mathrm{mU}^{-1} \mathrm{~g}^{-1}\right.$ tissue $)$ & $2.3(1.8$ to 2.7$)$ & $2.7(2.1$ to 3.3$)$ & +17 & 0.22 \\
\hline LPL rate of action (nmol min ${ }^{-1} 100 \mathrm{~g}^{-1}$ tissue) & $83(50$ to 115$)$ & $101(66$ to 136$)$ & +18 & 0.39 \\
\hline
\end{tabular}

Values are means $(95 \% \mathrm{CI})$

LPL mass and activity transport rates and LPL rate of action were calculated by multiplying the arterio-venous difference for LPL activity,

LPL mass and plasma triglycerides, respectively, across the tissue with the tissue blood flow and accounting for haematocrit. All measurements were made in the fasting state except for the tissue biopsies (mRNA and adipose tissue activity), which were taken $5 \mathrm{~h}$ after a standardised meal. The sample for analysis of skeletal muscle $L P L$ mRNA was taken from the thigh

Statistical significances between treatments were calculated by Student's paired $t$-test

\section{Relationship between adipose tissue LPL mass transport and functional aspects of $L P L$}

Comparing adipose tissue and the forearm, only adipose tissue appeared to release LPL mass to any significant degree. We sought to determine the impact of the release of LPL mass from adipose tissue on systemic concentrations of LPL. The output of LPL mass from adipose tissue, expressed in nanograms per minute per one hundred grams of tissue, was multiplied by the total fat mass of each individual to estimate of the release of LPL mass from whole-body adipose tissue. Adipose tissue release of LPL mass positively correlated with systemic concentrations of LPL mass ( $r=0.47, p=0.007)$ (Fig. 1).

The release of LPL mass from adipose tissue, measured either after placebo or after rosiglitazone treatment, was not related to the LPL activity of the tissue, measured either as
LPL activity in the adipose tissue biopsy specimen (placebo, $r=-0.09, p=0.74$; rosiglitazone, $r=-0.18$, $p=0.49$ ) or as the physiological LPL activity quantified by the removal of triglycerides in the blood passing the tissue (LPL rate of action) (placebo, $r=-0.13, p=0.63$; rosiglitazone, $r=-0.12, p=0.64$, respectively). However, as expected, there was a positive relationship between adipose tissue LPL activity and the physiologically measured LPL rate of action $(r=0.50, p=0.049)$ on placebo, although this relationship was not detected after rosiglitazone treatment $(r=-0.18, p=0.49)$.

Release of LPL mass from adipose tissue (LPL mass transport rate) was weakly related to adipose tissue $L P L$ mRNA abundance $(r=0.34, p=0.056)$ when all observations were taken together (placebo and rosiglitazone), but the mRNA level were unrelated to the LPL activity measures (data not shown).
Fig. 1 Relationship between estimated whole-body adipose tissue LPL mass production rate and the plasma concentration of LPL mass. Filled circles, treated with placebo; open circles, treated with rosiglitazone

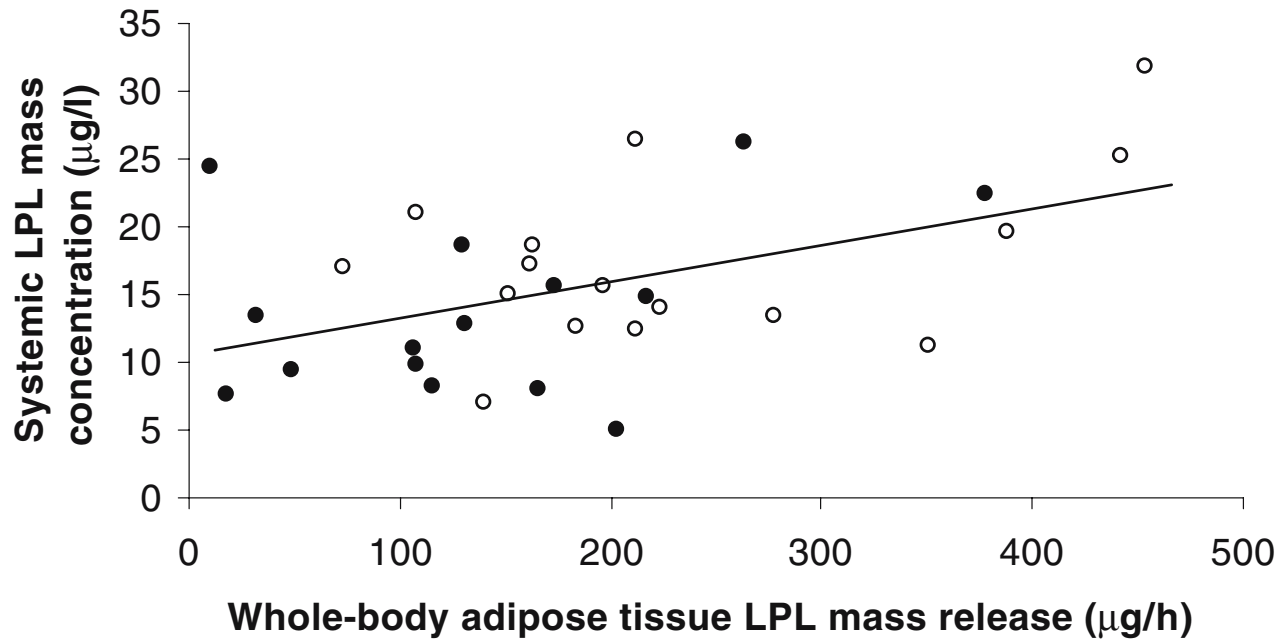


The treatment with rosiglitazone increased whole-body insulin sensitivity. The indicator of insulin sensitivity (homeostatic model assessment of insulin sensitivity [HOMA-S]) was significantly related to adipose tissue LPL mass release during placebo $(r=0.57, p=0.01)$, but not after rosiglitazone treatment $(r=0.23, p=0.37)$. Insulin sensitivity was unrelated to the LPL activity measures and LPL mRNA contents (data not shown). Insulin sensitisation in response to rosiglitazone (change in HOMA-S) was strongly related to the change in adipose tissue $L P L$ mRNA content $(r=0.81, p=0.001)$, but unrelated to change in adipose tissue LPL activity or LPL mass release.

\section{Discussion}

This study underscores the fundamental differences in regulation and turnover of LPL between human adipose tissue and skeletal muscle. It is the first to describe the tissue-specific effects on LPL of insulin sensitisation by rosiglitazone in patients with type 2 diabetes.

We used arterio-venous blood sampling technology to study the release of LPL from the tissues, which presumably reflects the end of the lifetime of LPL in the tissues, together with the release of LPL protein being produced in its inactive form. Adipose tissue appears to release significant amounts of inactive LPL, and tends to retain the active enzyme as far as possible. In contrast, the human forearm, which largely reflects skeletal muscle, releases only negligible amounts of LPL, most of which is active enzyme. Upon insulin sensitisation, adipose tissue further increases its release of inactive LPL, but the increased turnover of LPL protein in the tissue does not seem to have any consequence for the activity of the enzyme. Since rosiglitazone boosted LPL mRNA with a concomitant increase in LPL protein production without any increase in LPL activity in adipose tissue, it would be important to understand the mechanisms by which active LPL is inactivated in the tissue. This is probably a fundamental mechanism regulating the fed-to-fasted reduction in LPL activity seen in adipose tissue. Understanding of this mechanism might open novel targets for interfering with the LPL activity in the tissue.

Comparing the relationship between activity and mass of LPL released from muscle and adipose described here with a recently published paper, in which the specific activity of post-heparin plasma was quantified using the same assays as used here [22], we can estimate from the arterio-venous differences that the specific activity of LPL leaving muscle is in the range of 70 to $85 \%$ of that seen in post-heparin plasma, whereas the corresponding figure for adipose tissue is less than $1 \%$. However, in response to rosiglitazone the proportion of active LPL being released from skeletal muscle decreased drastically and the specific activity of the released enzyme would only correspond to something in the range of $15 \%$ of that seen in post-heparin plasma [22].

LPL is produced by adipocytes and transported to endothelial binding sites, to which active LPL displays high affinity $[23,24]$. As the inactive LPL does not have the same binding affinity to these sites, it may be readily released from the tissue. With the techniques used here, this can be quantified as a positive arterio-venous balance for LPL mass across adipose tissue. Although some of this LPL release may be due to adipocyte secretion of inactive LPL, it is not known whether some of the enzyme actually reaches the endothelial binding sites in its active form and thereafter undergoes rapid inactivation and release. This scenario could be part of the well-established fed-to-fasted regulation of LPL activity in adipose tissue, which is largely regulated by post-transcriptional events. It is therefore not surprising that the LPL mRNA content in adipose tissue is unrelated to either tissue LPL activity or physiologically quantified LPL rate of action. However, the release of LPL mass from adipose tissue was related to $L P L$ mRNA content, which might suggest that the mRNA content is a determinant of overall LPL production, irrespective of whether it has been produced as active or inactive enzyme. It seems plausible that the overall removal of LPL from the tissue occurs mostly through dissociation of LPL from endothelial binding sites and as a consequence the appearance of LPL mass in plasma, rather than through the re-uptake of inactivated enzyme by the tissue. It was also interesting to observe that the rate of release of LPL mass from adipose tissue correlated well with the systemic concentration of LPL, suggesting that a production rate of LPL mass from adipose tissue determines the systemic concentration of LPL. This relationship appeared to be augmented in response to the insulin sensitisation; adipose tissue released more inactive LPL in response to rosiglitazone and the systemic concentration of LPL mass was increased in line with this.

The striking difference between forearm and adipose tissue release of LPL suggests that the endothelial binding sites for LPL differ between the tissues. It is certainly possible that some aspects of LPL regulation in the tissues occur through the regulation of endothelial binding sites, which theoretically could be mediated by regulation of cellsurface expression of heparan sulphate proteoglycans. Very little is known about nutritional regulation of proteoglycans, but it has recently been observed that insulin increased the shedding of syndecan ectodomains on adipocytes, which promote LPL transport [25]. In skeletal muscle, the overall output of LPL was small and a significant amount of the little enzyme that escaped from the tissue was actually active. This might suggest that the presence of endothelial binding sites limits the endothelial 
expression of active enzyme in muscle. In contrast, adipose tissue appears to have plenty of endothelial binding sites; in fact there were even signs of removal of active enzyme from the blood passing through the tissue, which confirms a previous observation using similar technology [17]. The effect of rosiglitazone to reduce LPL activity transport rate in the forearm and to increase the extraction of active LPL in adipose tissue might suggest that peroxisome proliferator-activated receptor gamma agonists, or insulin sensitisation, increase the endothelial binding sites for LPL.

This is the only study to have examined LPL mRNA abundance, LPL mass and transport, i.e. release into the blood, in specific tissues of patients with type 2 diabetes in response to insulin sensitisation. Others have described increase of LPL mass in response to thiazolidinediones [26, 27].

Systemic concentrations of LPL mass have been correlated with insulin sensitivity [8]. Indeed, it has even been suggested that LPL mass in plasma is a marker for the metabolic syndrome, and this study would support this notion. It can also be deduced from our data that the increase in LPL mass is likely to originate from increased release of LPL mass from adipose tissue upon insulin sensitisation.

Acknowledgments F. Karpe is a Wellcome Trust Senior Clinical Research Fellow. G. D. Tan was an MRC clinical training fellow. The rosiglitazone treatment study was sponsored by GlaxoSmithKline. LPL analyses were supported by the Swedish Research Council Grant 12203 .

Duality of interest None of the authors have any duality or conflict of interest to declare.

\section{References}

1. Simsolo RB, Ong JM, Saffari B, Kern PA (1992) Effect of improved diabetes control on the expression of lipoprotein lipase in human adipose tissue. J Lipid Res 33:89-95

2. Taskinen MR, Nikkila EA, Kuusi T, Harmo K (1982) Lipoprotein lipase activity and serum lipoproteins in untreated type 2 (insulinindependent) diabetes associated with obesity. Diabetologia 22:46-50

3. Taskinen MR, Nikkila EA, Nousiainen R, Gordin A (1981) Lipoprotein lipase activity in adipose tissue and skeletal muscle of human diabetics during insulin deprivation and restoration. Scand J Clin Lab Invest 41:263-268

4. Nikkila EA, Huttunen JK, Ehnholm C (1977) Postheparin plasma lipoprotein lipase and hepatic lipase in diabetes mellitus. Relationship to plasma triglyceride metabolism. Diabetes 26:11-21

5. Miyashita Y, Shirai K, Itoh Y et al (2002) Low lipoprotein lipase mass in preheparin serum of type 2 diabetes mellitus patients and its recovery with insulin therapy. Diabetes Res Clin Pract 56: 181-187

6. Hanyu O, Miida T, Obayashi K et al (2004) Lipoprotein lipase (LPL) mass in preheparin serum reflects insulin sensitivity. Atherosclerosis 174:385-390

7. Bengtsson-Olivecrona G, Olivecrona T (1992) Assay of lipoprotein lipase and hepatic lipase. Oxford University Press, Oxford, pp 170-184

8. Miyashita Y, Shirai K (2005) Clinical determination of the severity of metabolic syndrome: preheparin lipoprotein lipase mass as a new marker of metabolic syndrome. Curr Med Chem Cardiovasc Hematol Agents 3:377-381

9. Rip J, Nierman MC, Wareham NJ et al (2006) Serum lipoprotein lipase concentration and risk for future coronary artery disease. The EPIC-Norfolk Prospective Population Study. Arterioscler Thromb Vasc Biol 26:637-642

10. Merkel M, Eckel RH, Goldberg IJ (2002) Lipoprotein lipase: genetics, lipid uptake, and regulation. J Lipid Res 43:1997-2006

11. Mead JR, Irvine SA, Ramji DP (2002) Lipoprotein lipase: structure, function, regulation, and role in disease. $\mathrm{J}$ Mol Med $80: 753-769$

12. Wu G, Brouckaert P, Olivecrona T (2004) Rapid downregulation of adipose tissue lipoprotein lipase activity on food deprivation: evidence that TNF-alpha is involved. Am J Physiol Endocrinol Metab 286:E711-E717

13. Ong JM, Kern PA (1989) Effect of feeding and obesity on lipoprotein lipase activity, immunoreactive protein, and messenger RNA levels in human adipose tissue. J Clin Invest 84:305-311

14. Bergo M, Wu G, Ruge T, Olivecrona T (2002) Down-regulation of adipose tissue lipoprotein lipase during fasting requires that a gene, separate from the lipase gene, is switched on. J Biol Chem 277:11927-11932

15. Wu G, Olivecrona G, Olivecrona T (2005) Extracellular degradation of lipoprotein lipase in rat adipose tissue. BMC Cell Biol 6:4

16. Ruge T, Bergo M, Hultin M, Olivecrona G, Olivecrona T (2000) Nutritional regulation of binding sites for lipoprotein lipase in rat heart. Am J Physiol Endocrinol Metab 278:E211-E218

17. Karpe F, Olivecrona T, Olivecrona G et al (1998) Lipoprotein lipase transport in plasma: the role of muscle and adipose tissue in regulation of plasma lipoprotein lipase concentrations. J Lipid Res 39:2387-2393

18. Tan GD, Fielding BA, Currie JM et al (2005) The effects of rosiglitazone on fatty acid and triglyceride metabolism in type 2 diabetes. Diabetologia 48:83-95

19. Frayn KN, Coppack SW (2001) Assessment of white adipose tissue metabolism by measurement of arteriovenous differences. Methods Mol Biol 155:269-279

20. Holm C, Olivecrona G, Ottosson M (2001) Assays of lipolytic enzymes. Methods Mol Biol 155:97-119

21. Tornvall P, Olivecrona G, Karpe F, Hamsten A, Olivecrona T (1995) Lipoprotein mass and activity in plasma and their increase after heparin are separate parameters with different relations to plasma lipoproteins. Arterioscler Thromb Vasc Biol 15:1086-1093

22. Eriksson JW, Buren J, Svensson M, Olivecrona T, Olivecrona G (2003) Postprandial regulation of blood lipids and adipose tissue lipoprotein lipase in type 2 diabetes patients and healthy control subjects. Atherosclerosis 166:359-367

23. Lookene A, Savonen R, Olivecrona G (1997) Interaction of lipoproteins with heparan sulfate proteoglycans and with lipoprotein lipase. Studies by surface plasmon resonance technique. Biochemistry 36:5267-5275

24. Lookene A, Zhang L, Hultin M, Olivecrona G (2004) Rapid subunit exchange in dimeric lipoprotein lipase and properties of the inactive monomer. J Biol Chem 279:49964-49972

25. Reizes O, Goldberger O, Smith AC, Xu Z, Bernfield M, Bickel PE (2006) Insulin promotes shedding of syndecan ectodomains from 3T3-L1 adipocytes: a proposed mechanism for stabilization of extracellular lipoprotein lipase. Biochemistry 45:5703-5711

26. Shirai K, Itoh Y, Sasaki H et al (1999) The effect of insulin sensitizer, troglitazone, on lipoprotein lipase mass in preheparin serum. Diabetes Res Clin Pract 46:35-41

27. Nagashima K, Lopez C, Donovan D et al (2005) Effects of the PPARgamma agonist pioglitazone on lipoprotein metabolism in patients with type 2 diabetes mellitus. J Clin Invest 115: $1323-1332$ 